\title{
The Use of WhatsApp Messaging Improves Communication in Surgery Team
}

\author{
Dr. Ajay Sharma ${ }^{1 *}$, Dr. Sanjay Singhal ${ }^{2}$ \\ ${ }^{1}$ Assistant Prof Department of Gastrointestinal Surgery, Mahatma Gandhi Medical College Jaipur, Rajasthan, India \\ ${ }^{2}$ Professor Department of Surgery, Mahatma Gandhi Medical College Jaipur, Rajasthan India
}

\author{
DOI: $10.36348 /$ SJMPS.2019.v05i10.014 \\ | Received: 16.10.2019 | Accepted: 25.10.2019 | Published: 30.10 .2019 \\ *Corresponding author: Dr. Ajay Sharma
}

\section{Abstract}

Introduction: Most common mode of communication between medical professionals is by visits, telephone and mobile phone calls, meetings of doctors, and WhatsApp usage. WhatsApp has group communication and makes sending of images and videos on same group its usage most effective. Material and Methods: We did a 3 months prospective study in our Surgical Gastroenterology unit (of 15 professionals) using English and Hindi language and compared WhatsApp communication with communication by by telephone mobile phone. Results: Of the total 3462messages delivered 3219 $(92.7 \%)$ were of patient care only. There were $71(2.05 \%)$ messages related to administrative details, 5.4\%(188) messages relates to teaching and academic. Multimedia messages were 145 (4.2\%). Time taken to reply a message in routine working hours was found to be of 8 seconds to 25 minutes. Messages done by land line or mobile phone call systems were 184 and the time spend on each was approx 2 to 17 minutes. It was a common opinion of all members was that it's a very useful tool, it saved time compared to the traditional methods of calling and replying. Conclusion: WhatsApp is a free of cost, easily available and a very reliable mode of use for medical practitioners. It is a development over the traditional telephone or call on mobile phone.

Keywords: WhatsApp, Mobile, Telephone, Communication, Surgical groups, Images, Video call.

Copyright @ 2019: This is an open-access article distributed under the terms of the Creative Commons Attribution license which permits unrestricted use, distribution, and reproduction in any medium for non-commercial use (NonCommercial, or CC-BY-NC) provided the original author and source are credited.

\section{INTRODUCTION}

Timely communication between the surgical team members and between surgeon and anaesthetists effectively improves the patients outcome. Communication includes the details of the patient condition and reports of patient, information of imaging \{X Ray, Contrast enhanced computerised tomography (CECT)scans, Magnetic resonance imaging (MRI) etc . Most commonly used modes to achieve these is by visit by a senior member of team to emergency and radiology room, telephonic communication, preoperative meetings, using emails and ground phones. A checklist seems mandatory for effective functioning but there is always a need to improve timely communication. [1-2]. Working up the patient before surgery require good message communication between team members. The newer generation is using smartphone more commonly. Various applications help us pass on the information faster. One of such communication system is WhatsApp. It has a group communication feature which makes its use very practical.
We did a 3 months prospective study in our Surgical Gastroenterology unit and compared WhatsApp communication with communication by by telephone mobile phone.

\section{MATERIALS AND METHODS}

A free of cost application to be used in smart phones and by most medical community was easily available in the form of WhatsApp (WhatsApp Inc., Mountain View, CA, USA). WhatsApp was easy to use in group or on personal basis and has indicator to show if the message is sent and or read in time, with additional qualities of sending multimedia messages as images, videos, and attachment of files. A Whatsapp group was made for purpose related to gastrointestinal surgery unit only. The group included a total of 15 professionals (including Surgeons, anaesthetist, Senior residents, nursing staff). Languages used for messaging was English or Hindi as preferred by users. The group on WhatsApp helped rapid communication of the work related details and questions by the juniors. The messages used during study duration were used for data analysis. Multiple phone calls made on hospital phone 
and mobile to mobile or mobile to landline were also analysed during the same period.

A simple questioner was used to discuss with each member if they found any system more beneficial over the other systems.

\section{RESULTS}

It was found that WhatsApp was already been used by all the members of the team for their personal day to day usage and hence required no specific training.

During this three month period a total of 3462 messages were sent in the group. Of the total messages delivered $3219(92.7 \%)$ messages were for the patient care only. These messages were having information on new admissions, investigations, progress of the patient, images of Chest X Ray, CT scan, MRI films, day to day changes in treatment of patients (other than those changes which were done on morning and evening rounds). There were $71(2.05 \%)$ messages related to administrative details in relation to staff duty, holiday posting, emergency duty etc. Additional 5.4\%(188) messages were related to teaching academic discussion and research related to subject. A total of 145 (4.2\%) messages were multimedia messages these included ABG reports, radiograph images CT Scan and MRCP images and videos, and pictures of wounds and drains placed. It was ensured that none of the images or messages should show patients face or name so as to keep the patients personal information safe. Reply to a message was received in duration of 8 seconds to 25 minutes in routine hours for urgent messages. Late night routine messages were responded in 6 to 8 hours.

A series of 184 communications were done by land line or mobile phone call systems. It was found that the length of time spend on a call was approx 2 to 17 minutes. It was found that with almost 63 (34.2\%) telephonic communications a support of WhatsApp message was required to confirm the lab reports or multimedia messages.

In the Miscellaneous communications section we found unexpectedly 1) social group messages to be $84(2.4 \%)$ conversations and 2) sessions of interest/wishes (like good morning and Happy Birthday) to the team were $68(1.9 \%)$ conversations..

All the members of the team who participated in WhatsApp group were of the opinion that it's a very useful tool, it saved them a significant amount of time and effort compared to the traditional methods of calling and replying. All felt it was not a hindrance or a distraction rather it was a support in their duty and day to day work.

\section{DISCUSSION}

In todays times the technology is being used in every aspect and is utilised to its maximum beneficial effect. Same is happening in hospital settings also weather it is in operation instrumentation, advanced microscopes, laparoscopic advancements etc. With the availability of the smart phones and their improved connectivity it has made their usage more prevalent for medical professionals with studies reporting between $74 \%-85 \%$ of doctors using a smartphone $[3,4]$.

The traditional phones are considered to be less efficient in comparison to the present system [5]. One of the initial study by Wani et al. showed WhatsApp (used in 116 episodes) as a more common method of communication among plastic surgeons for academic usage as well as good patient management [6]. Johnston, et al. [7] concluded that for emergency surgical teams WhatsApp safe and efficient form of communication. They further addressed that WhatsApp reduces communication barriers between senior and junior colleagues. Jhonston included interns and residents in their group and found that interns are most common to ask clinical questions and residents were most active to respond to work in instruction received in WhatsApp [7]. One study used WhatsApp to send images of radiographs and Videos of CT scans like in our study but they used it mainly for maxilofascial trauma[8]. Even Giordano, et al. reported use of of tibial plateau fractures radiographs on WhatsApp and advocated its use in the clinical setting [9].

Our study was intradepartmental, with all participants finding the use of WhatsApp made communication easier and quicker. The intermediate faculty and senior residents found that the data which was not available to them on regular basis (when data transfer was on telephonic communication) is now more informative for surgical planning. In addition all senior and junior team members were of common opinion that with WhatsApp usage they now had more time while performing duty and this usage made them more active in participating in academic discussions and increasing basic and advanced knowledge.

A study of cardiology segment [10] reported that with the WhatsApp usage they had more rapid percutaneous intervention in myocardial infarction patients. They shared electrocardiograph rapid imaging with the interventional radiologist elsewhere and not in their hospital. Simultaneously this usage of Whats app also resulted in less false positive reporting of ST segment elevation. [10].

A general opinion is that many communications related to same message can lead to potential problems like possibility of error occurring. A review by Rivera-Rodriguez and Karsh [11] was of opinion that though interruption is likely but it does not 
always have negative effect and it may be necessary for practicing good health care.

There is some negative usage of WhatsApp in medical devises. It has been shown to interfere with cardiac usage or pacemakers [12] This happened specially when used with in $10 \mathrm{~cm}$ distance from the equipment [13] this was found with the older models of the instruments used and present opinion is that newer generation smart phones can be used upto 1 meter of the equipments.

There were many discussions regarding the patient safety while using the WhatsApp messages. End to end encryption which means that even the company cant make use of the message and this message cant be stolen, in simple words makes it safe for usage. More over there is always a risk of breaching patient confidentiality but it depends on the team using it. We do agree that potential of misuse exists but this should not limit the development of the science and usage of the advanced technologies available with the development world wide.

\section{Limitations of the study}

This study has several limitations. Main purpose was to evaluate our initial experience. It lacks details such as the time taken to perform the responses when a question was done or the degree of satisfaction of the users. It lacks the information about the benefit to the patient as the two groups were not comparable. However, it is noticeable that this group is still active at the end of completion of the study.

\section{CONCLUSIONS}

WhatsApp is a free of cost, easily available and a very reliable mode of use for medical practitioners. It is a development over the traditional telephone or call on mobile phone. If adequately used it can improve the communication, teaching and patient care.

\section{Authors' contributions}

Dr Ajay Sharma is the corresponding author. He has coordinated the works done from the beginning to the end. WhatsApp group was made under his supervision and guidance. Data collection, analysis and document works were organized by him. Dr Sanjay Singhal assisted in collecting the group information. He also contributed in the data collection. Both the authors have read understood and approved the manuscript and its contents.

\section{Competing interests}

There is no competing interest in our research.

\section{Consent for publication}

Both the participants were given prior knowledge about publishing the results after the end of the research.

\section{REFERENCES}

1. France, D. J., Leming-Lee, S., Jackson, T., Feistritzer, N. R., \& Higgins, M. S. (2008). An observational analysis of surgical team compliance with perioperative safety practices after crew resource management training. The American Journal of Surgery, 195(4), 546-553.

2. Ren, Y., Kiesler, S., \& FuSSEll, S. R. (2008). Multiple group coordination in complex and dynamic task environments: Interruptions, coping mechanisms, and technology recommendations. Journal of Management Information Systems, 25(1), 105-130.

3. Franko, O. I., \& Tirrell, T. F. (2012). Smartphone app use among medical providers in ACGME training programs. Journal of medical systems, 36(5), 3135-3139.

4. Payne, K. F. B., Wharrad, H., \& Watts, K. (2012). Smartphone and medical related App use among medical students and junior doctors in the United Kingdom (UK): a regional survey. BMC medical informatics and decision making, 12(1), 121.

5. Wu, R., Rossos, P., Quan, S., Reeves, S., Lo, V., Wong, B., ... \& Morra, D. (2011). An evaluation of the use of smartphones to communicate between clinicians: a mixed-methods study. Journal of Medical Internet Research, 13(3), e59.

6. Wani, S. A., Rabah, S. M., AlFadil, S., Dewanjee, N., \& Najmi, Y. (2013). Efficacy of communication amongst staff members at plastic and reconstructive surgery section using smartphone and mobile WhatsApp. Indian journal of plastic surgery: official publication of the Association of Plastic Surgeons of India, 46(3), 502.

7. Johnston, M. J., King, D., Arora, S., Behar, N., Athanasiou, T., Sevdalis, N., \& Darzi, A. (2015). Smartphones let surgeons know WhatsApp: an analysis of communication in emergency surgical teams. The American Journal of Surgery, 209(1), 45-51.

8. Kelahmetoglu, O., \& Firinciogullari, R. (2015). Efficient utility of WhatsApp: From computer screen to the surgeon's hand to determine maxillofacial traumas. Journal of Craniofacial Surgery, 26(4), 1437.

9. Giordano, V., Koch, H. A., Mendes, C. H., Bergamin, A., de Souza, F. S., \& do Amaral, N. P. (2015). WhatsApp Messenger is useful and reproducible in the assessment of tibial plateau fractures: inter-and intra-observer agreement study. International journal of medical informatics, 84(2), 141-148. 
10. Astarcioglu, M. A., Sen, T., Kilit, C., Durmus, H. I., Gozubuyuk, G., Kalcik, M., ... \& Amasyali, B. (2015). Time-to-reperfusion in STEMI undergoing interhospital transfer using smartphone and WhatsApp messenger. The American journal of emergency medicine, 33(10), 1382-1384.

11. Rivera-Rodriguez, A. J., \& Karsh, B. T. (2010). Interruptions and distractions in healthcare: review and reappraisal. BMJ Quality \& Safety, 19(4), 304312.
12. Saraf, S. (2009). Use of mobile phone in operating room. Journal of Medical Physics/Association of Medical Physicists of India, 34(2), 101.

13. Naegeli, B., Osswald, S., Deola, M., \& Burkart, F. (1996). Intermittent pacemaker dysfunction caused by digital mobile telephones. Journal of the American College of Cardiology,27(6), 14711477. 